\title{
A multi-centre randomised phase III trial of Dexamethasone vs Dexamethasone and diethylstilbestrol in castration-resistant prostate cancer: immediate vs deferred Diethylstilbestrol
}

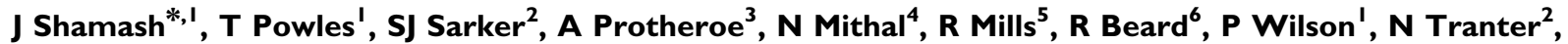 \\ N O'Brien', 5 McFaul' and T Oliver ${ }^{2}$
}

'St Bartholomew's Hospital, 7th Floor, Gloucester House, Little Britain, UK; ${ }^{2}$ Queen Mary University London, London, UK; ${ }^{3}$ Churchill Hospital, Oxford, UK; ${ }^{4}$ Kent and Canterbury Hospital, Canterbury, UK; ${ }^{5}$ Norfolk and Norwich University Hospital, Norwich, UK; ${ }^{6}$ Worthing Hospital, Worthing, UK; ${ }^{7}$ Queens Hospital, Romford, UK

BACKGROUND: The role of further hormone therapy in castration-resistant prostate cancer (CRPC) remains unclear. We performed a multi-centre randomised phase III study comparing the use of Dexamethasone, Aspirin, and immediate addition of Diethylstilbestrol (DAiS) vs Dexamethasone, Aspirin, and deferred (until disease progression) addition of Diethylstilbestrol (DAdS).

METHODS: From 200 I to 2008, 270 men with chemotherapy-naive CRPC were randomly assigned, in a I : I ratio, to receive either DAiS or DAdS. They were stratified for performance status, presence of bone metastases, and previous normalisation of prostatespecific antigen (PSA) to androgen deprivation. The study end points were the proportion of patients achieving a 50\% PSA response, progression-free survival (PFS), overall survival, and quality of life. Intention-to-treat analysis was carried out. The effect of treatment was studied first by Kaplan-Meier curves and log-rank test, and finally through multivariable stratified Cox's proportional hazards model adjusting for the effects of possible baseline prognostic factors. Quality of life was analysed using multivariate analysis of variance.

RESULTS: At study entry, the median age was 76 years (inter-quartile range: $70-80$ years), the median PSA was $79 \mathrm{ng} \mathrm{ml}{ }^{-1}$, and $76 \%$ of the cohort had metastatic disease. The response rates for DAiS (68\%) and DAdS (64\%) were not significantly different $(P=0.49)$. Similar to the response rate, neither the PFS (median $=8.1$ months for both arms) nor the overall survival (I9.4 vs I8.8 months) differed significantly between the DAiS and DAdS groups $(P>0.20)$. However, the response rate for the DAiS (68\%) was significantly higher than the response rate of DA (before adding Diethylstilbestrol) $(50 \%)(P=0.002)$. Similarly, the median time to progression for DAiS (8.6 months) was significantly longer than that of DA ( 4.5 months) $(P<0.00 \mathrm{I})$. Multivariable analysis showed that patients with previous haemoglobin $\geqslant 1 \mathrm{I} \mathrm{g} \mathrm{dl}^{-1}$ decreased the risk of death significantly (hazard ratio: $0.44,95 \% \mathrm{Cl}$ : 0.25-0.77). Patients treated with previous anti-androgens alone had more than 5 times more risk of death compared with patients treated with gonadorelin analogues throughout their castration-sensitive phase. Treatment sequencing did not affect the quality of life but pretreatment performance status did. The incidence of veno-thromboembolic events was $22 \%(n=28)$ in DAiS and $11 \%(n=14)$ in the DA arm $(P=0.02)$. Painful gynaecomastia occurred in only $1 \%$ on DA, whereas in $40 \%$ on DAiS $(P=0.001)$.

CONCLUSION: Dexamethasone and immediate Diethylstilbestrol resulted in neither higher PSA response rate nor higher PFS compared with Dexamethasone with deferred Diethylstilbestrol. There was no suggestion of significantly improved overall survival or quality of life. Given the significantly higher toxicity of Diethylstilbestrol, deferring Diethylstilbestrol until failure of Dexamethasone is the preferred strategy when using these agents in CRPC.

British Journal of Cancer (201I) I 04, 620-628. doi:I0.1038/sj.bjc.6606I02 www.bjcancer.com

Published online I February 20 II

(C) 201 I Cancer Research UK

Keywords: CRPC; Dexamethasone; Diethylstilbestrol; treatment sequencing

Prostate cancer is the most common cancer in men in Europe and in the United States. The frequency of patients presenting with disease has risen following the introduction of the prostate-specific antigen (PSA) blood test. The management of locally advanced or

\footnotetext{
*Correspondence: Dr J Shamash;

E-mail: jonathan.shamash@bartsandthelondon.nhs.uk

Received 17 November 2010; revised 26 December 2010; accepted 29 December 20 I0; published online I February 201 I
}

metastatic disease is initially carried out with androgen deprivation therapy, in the form of bilateral orchidectomy or gonadorelin analogues (GnRHs), with or without a peripheral anti-androgen (AA) (Hellerstedt and Pienta, 2002)) with the addition of radiotherapy to the prostate in those with locally advanced disease (Mottet et al, 2010; Warde et al, 2010). When this treatment fails, usually after $1-3$ years, the disease is termed castration-resistant prostate cancer (CRPC) (Scher et al, 2008)), and the use of further endocrine agents and/or chemotherapy is common. Chemotherapy has been shown to improve symptoms (Tannock et al, 1996), and 
docetaxel (Petrylak et al, 2004; Tannock et al, 2004), in particular, has more recently been shown to prolong life by $2-3$ months compared with mitoxantrone. The lack of robust randomised data regarding the timing and choice of further endocrine agents in this setting has resulted in no clear consensus.

A randomised study has confirmed that prednisone is superior to flutamide in terms of quality of life (Fossa et al, 2001). Further phase II studies have suggested that Dexamethasone results in superior PSA responses (the proportion of patients achieving a $50 \%$ reduction in PSA) (Nishimura et al, 2000; Venkitaraman et al, 2008) when compared with that observed with either prednisone/ prednisolone (Tannock et al, 1996) or hydrocortisone (Kantoff et al, 1999). Whether this translates to a survival advantage over other steroids is unclear.

Oestrogens are clearly active in prostate cancer and were originally thought to function by inducing androgen deprivation indirectly. The xeno-oestrogen Diethylstilbestrol has been the most widely investigated oestrogen. More recently it has been observed that this drug is active in CRPC (Farrugia et al, 2000), the mechanism of this may include binding to the androgen receptor. However, Diethylstilbestrol has significant side effects, which has limited its use. These include veno-thromboembolic events (VTEs), cardiac failure, stroke, and gynaecomastia.

The combination of corticosteroids and low-dose Diethylstilbestrol (1 mg per day) is active in CRPC (Farrugia et al, 2000). The optimal timing of the two drug groups had not been elucidated. We therefore conducted a pragmatic randomised phase 3 trial in locally advanced or metastatic disease to see whether the drugs should be given concurrently or in sequence. As aspirin is frequently given in an attempt to reduce the risk of VTEs, yet inhibiting cyclooxygenase 2 might inhibit prostate cancer growth (Yoshimura et al, 2000); it was decided that those patients allocated to steroids alone would receive aspirin, to counter the criticism that any benefit of Diethylstilbestrol were in fact because of aspirin rather than to the Diethylstilbestrol.

Our objective in this trial was to compare the immediate $v s$ deferred addition of Diethylstilbestrol with Dexamethasone and aspirin in treating patients with CRPC. The comparison was done in terms of response rate, time to progression, progression-free survival (PFS), overall survival, and quality of life. As patients with CRPC form a very heterogeneous group, stratified randomisation was carried out on the basis of three established factors.

\section{PATIENTS AND METHODS}

\section{Study design}

This was a multi-centre, randomised, open-label phase III trial to compare two treatment strategies in patients with newly diagnosed CRPC: the trial compared the use of Dexamethasone, Aspirin, and immediate addition of Diethylstilbestrol (DAiS) vs Dexamethasone, Aspirin, and deferred (until disease progression) addition of Diethylstilbestrol (DAdS). The study was approved by a multicentre research ethics committee with local ethical approval sought by each recruiting centre. All patients gave written informed consent before enrolling in the study. Patients were randomised to the trial with a $1: 1$ ratio by stratifying according to performance status (ECOG: 0 vs 1-3), whether or not they achieved a PSA $<4.5 \mathrm{ng} \mathrm{ml}^{-1}$ with initial androgen deprivation, and whether or not they had a positive or negative bone scan before study entry. The study was performed in accordance with the Declaration of Helsinki as well as with the Good Clinical Practice Guidelines.

\section{Patient population}

Criteria for patients to enter the study population were as follows: they had to have a diagnosis of prostate cancer, be over 18 years old, and have an ECOG performance status $0-3$. They were also required to be biochemically castrate (testosterone $<1.5 \mathrm{nmol} \mathrm{ml}^{-1}$ or if not to have failed the addition of a peripheral AA), have a PSA $>5 \mathrm{ng} \mathrm{ml}^{-1}$, and disease progression determined by rising PSA and/or progression of symptoms, that is, increasing pain from documented bone metastases, despite stable but elevated PSA. Patients required adequate bone marrow reserve $\left(\mathrm{WBC}>3 \times 10^{9}\right.$ per litre and platelets $>50 \times 10^{9}$ per litre) and adequate liver function (bilirubin less than $2 \times$ upper limit of normal and ALT or AST less than $3 \times$ upper limit of normal).

The following were exclusion criteria for the study - those with previous thrombombolic disease (including stroke), angina, and poorly controlled diabetes mellitus. Previous uncomplicated myocardial infarction was not an exclusion criterion. It was up to the individual site to decide whether or not to continue $\mathrm{GnRH}$, once starting the study. Once a site had decided on their approach they were asked to maintain it for all the patients that were recruited.

\section{Treatment plan and outcome measures}

Patients were randomly assigned to either DAiS - Dexamethasone $2 \mathrm{mg}$ per day, aspirin $75 \mathrm{mg}$ per day, Diethylstilbestrol $1 \mathrm{mg}$ per day with ranitidine $150 \mathrm{mg}$ two times per day, until symptomatic or PSA progression, or to DAdS - Dexamethasone $2 \mathrm{mg}$ per day and aspirin $75 \mathrm{mg}$ per day with ranitidine $150 \mathrm{mg}$ two times per day. In the DAdS arm, Diethylstilbestrol was added on PSA progression that was confirmed 1 week later.

Time to PSA progression was determined using the PCWG 1 criteria (Bubley et al, 1999); for patients who achieved at least a $50 \%$ decrease in PSA, progression was defined as an increase in PSA of at least $50 \%$ above the nadir with an absolute increase of $5 \mathrm{ng} \mathrm{ml}^{-1}$. For those with less than $50 \%$ decrease in PSA, PSA progression was defined as an increase of at least $25 \%$ above the nadir, or in the absence of a PSA decrease, an increase of at least $25 \%$ above baseline. In either case, the increase had to be an absolute value of at least $5 \mathrm{ng} \mathrm{ml}^{-1}$. For the DAdS group, PSA response was defined if a patient responded at least once either before receiving Diethylstilbestrol or after. The use of bisphosphonates was permitted throughout the study. The time to progression (TTP) was defined as the time from randomisation to the first observation of disease progression. Progression-free survival was defined as the time from randomisation to the first observation of disease progression or death. In the DAdS group, those who received Diethylstilbestrol at the progression of disease, their TTP (PFS) was measured from randomisation to the first observation of disease progression (progression or death) after receiving Diethylstilbestrol. Survival time was measured from the randomisation into the study drug to date of death. Patients with no record of death up to the end of study were censored at their last date of assessment.

\section{Assessments}

Patients were assessed monthly and were asked to complete a quality of life assessment as part of the study - EORTC QLQ C30 with site-specific module PR25, which specifically assessed lower urinary tract symptoms and erectile function. They were weighed at each appointment and had blood drawn for PSA, urea and electrolytes, liver function, and bone profile. Toxicity was recorded using the NCI Common Toxicity Criteria version 3.0. Patients who developed VTEs were recommended to continue hormonal therapy and start low-molecular weight heparin, and then oral anticoagulants (warfarin).

Following progression of disease, the patients were treated at the discretion of their physician or urologist. Information collected at initial assessment included haemoglobin, raised alkaline phosphatase $\left(\geqslant 130 \mathrm{IU}^{-1}\right)$, previous therapy (categorised as: $\mathrm{GnRH}, \mathrm{AA}$, maximum androgen blockade (MAB), radical treatment 
(radiotherapy and surgery)), and comorbidities (diabetes, myocardial infarction, and respiratory disease).

\section{Statistical analysis}

The sample size was determined to detect a clinically important difference (at least 15\%) in response rate between the two study arms. On the basis of the observed response rate to Dexamethasone, $2 \mathrm{mg}$ of $62 \%$ (Nishimura et al, 2000) and the response to Diethylstilbestrol, $1 \mathrm{mg}$ with corticosteroid of $78 \%$ (Farrugia et al, 2000 ), to detect a $16 \%$ difference $(62$ vs $78 \%$ ) between the two groups with $80 \%$ power, and $1: 1$ randomisation would require 130 patients in each arm (allowing for two dropouts in each arm) at 5\% level of significance. This was achieved using a two-sided $\chi^{2}$-test (Machin et al, 2008)). This size of the trial also has $85 \%$ power to detect 2 months difference between median TTP according to logrank test. Many investigators are finding that generally $5-10 \%$ change in overall quality of life score (1-100 scale) is considered significant by the patients. Therefore, it was assumed that $10 \%$ difference in overall quality of life change score between two treatment methods would be clinically important. The study would have $62 \%$ power to detect this difference with this specified sample size.

During the study, there was a period of time when the supply of Diethylstilbestrol was suspended and 12 patients required an alternative oestrogen. Therefore, an additional 12 patients were recruited to safeguard the power of the trial and an intention-totreat analysis was performed based on all randomised patients.

Univariate analyses were performed to examine differences in baseline characteristics between the two treatment groups (DAdS $v s$ DAiS) using $\chi^{2}$, two-sample $t$-tests, or Fisher's exact tests, as appropriate. Similarly, differences in toxicity between DA and DAiS were tested using $\chi^{2}$, two-sample $t$-tests, or Fisher's exact tests, as appropriate. The baseline hazard/risk of VTE was plotted using kernel density estimation, based on the DAiS group.

Univariate survival was examined using unadjusted KaplanMeier curves, with comparison between DAiS and DAdS by using the log-rank test. Stratified Cox proportional hazards model was applied to test the effect of treatment on overall survival adjusting for prognostic factors, including age, haemoglobin, alkaline phosphatise, previous therapy, Gleason score, and comorbidities. Pre-study androgen deprivation was highly correlated with the pre-treatment therapy. Therefore, only pre-treatment therapy was included in the multivariable Cox model. Regression diagnostics included Schoenfeld residuals. The sample was confined to complete cases for the multivariable analysis with no missing values in the considered prognostic factors. To assess selection bias because of restriction on complete cases, sensitivity analysis was performed.

Multivariate analysis of variance (MANOVA) was performed to see the effect of the two treatment approaches towards the quality of life (based on EORTC QLQ-C30) and prostate-specific quality of life (based on EORTC QLQ-PR-25). Percentage of change of scores from baseline was calculated for each repeated measurements and then they were averaged over the repetitions to apply MANOVA to test the differences in quality of life measures in terms of treatment DAdS vs DAiS. Intercooled STATA 10.1 (StataCorp., College Station, TX, USA) for Windows was used for the statistical analysis.

\section{RESULTS}

\section{Patient characteristics}

The patient characteristics at study entry are shown in Table 1 . The median age was 76 years (inter-quartile range (IQR): 70-80) and $76 \%$ had positive bone scans. The median PSA before study entry was $79.2 \mathrm{ng} \mathrm{ml}^{-1}$ (IQR: $179 \mathrm{ng} \mathrm{ml}^{-1}$ ) and $39.2 \%$ had a raised $\left(\geqslant 130 \mathrm{IU} \mathrm{l}^{-1}\right)$ alkaline phosphatase levels. Approximately $73 \%$ of patients had received a GnRH as their initial form of androgen deprivation. Approximately $62 \%$ of patients had previously normalised their PSA $\left(<4.5 \mathrm{ng} \mathrm{ml}^{-1}\right)$ to earlier androgen deprivation. The median time from starting androgen deprivation to study entry was 35 months (59 months for those with locally advanced disease and 29 months in those with metastatic disease). Among the non-metastatic group, median pre-study androgen deprivation for the DAiS group (41 months) was significantly lower than the 78 months for the DAdS group $(P=0.02)$. However, this is based on only 19 patients in each group and hence is not unexpected. Approximately $47 \%$ of patients continued androgen deprivation with a GnRH. Approximately $22 \%$ of patients had previous comorbidity (previous myocardial infarction, diabetes, or chronic obstructive pulmonary disease). The study flow diagram (CONSORT) is shown in Figure 1.

\section{Response to therapy}

The 50\% PSA response to therapy was recorded according to the PCWG criteria-1 (Bubley et al, 1999). Overall, 68\% of patients allocated to DAiS achieved a response as opposed to $64 \%$ of patients allocated to DAdS $(P=0.49)$. Seven patients $(2.7 \%)$ were not evaluable for response. There were two early deaths, three early withdrawals because of toxicity, and in two patients the data was insufficient to evaluate response. Similar to the response rate, neither the TTP nor the PFS differed significantly between the DAiS and DAdS groups $(P>0.70)$ (Table 2). However, the response rate for the DAiS (68\%) was significantly higher than the response rate of DA (before adding Diethylstilbestrol) $(50 \%)(P=0.002)$. Similarly, the median TTP for DAiS (8.6 months) was significantly longer than that of DA $(4.5$ months $)(P<0.001)$. The response to the addition of Diethylstilbestrol in those initially allocated to DA was $43 \%$, with a median duration of this response of 5 months. A significant proportion of patients in this group who could have received Diethylstilbestrol did not (35\%), the most common reason for this was toxicity on DA. All patients in the DAiS remained castrate throughout therapy, however $22 \%$ of patients allocated DAdS became non-castrate before the addition of Diethylstilbestrol. Their median overall time to progression was 8.4 months in this group (95\% CI: 7.4-22.1) vs 8.3 (95\% CI: $6.7-9.0)$ in the group that remained castrate $(P=0.071, \log$-rank test).

The overall survival from entry in to the study was 19.1 months (95\% CI: $16.8-21.4)$. There was no significant difference in overall survival when comparing the two arms; 19.4 months (95\% CI: $16.8-25.9)$ in the DAiS arm and 18.8 months (95\% CI: $15.8-20.4)$ in the DAdS arm. $(P=0.28)$ (Figure 2).

Patients received subsequent chemotherapy at the choice of the treating physician. In the DAdS group, $30 \%$ went on to have chemotherapy and their median survival was 20.0 months (95\% CI: 15.8-30.1) compared with 19.1 months (95\% CI: 13.5-22.1), $(P=0.53)$. In the DAiS group, $35 \%$ went on to receive chemotherapy and their median survival was 19.5 months (95\% CI: 15.4-25.9) compared with 24.1 months (95\% CI: 11.9 -could not be estimated) $(P=0.5)$.

Multivariable analysis using the Cox model (Table 3) showed that age was associated with an increased risk of death. Among other prognostic factors, having haemoglobin greater or equal to $11 \mathrm{~g} \mathrm{dl}^{-1}$ decreased the risk of death significantly (HR $0.44,95 \% \mathrm{CI}$ : $0.25-0.77)$. Previous therapy had a significant effect on overall survival $(P=0.01)$. Patients treated with AA alone had greater than 5 five times more risk of death compared with patients treated with GnRH. Although previous therapy and haemoglobin had significant effect on patients' overall survival, treatment sequence (DAiS $v s$ DAdS) did not have any significant effect on survival when adjusted for other baseline factors $(P=0.16)$. Sensitivity analysis, carried out to check for selection bias because of complete case analysis, showed that complete case analysis was unbiased. 
Table I Patients' characteristics at presentation

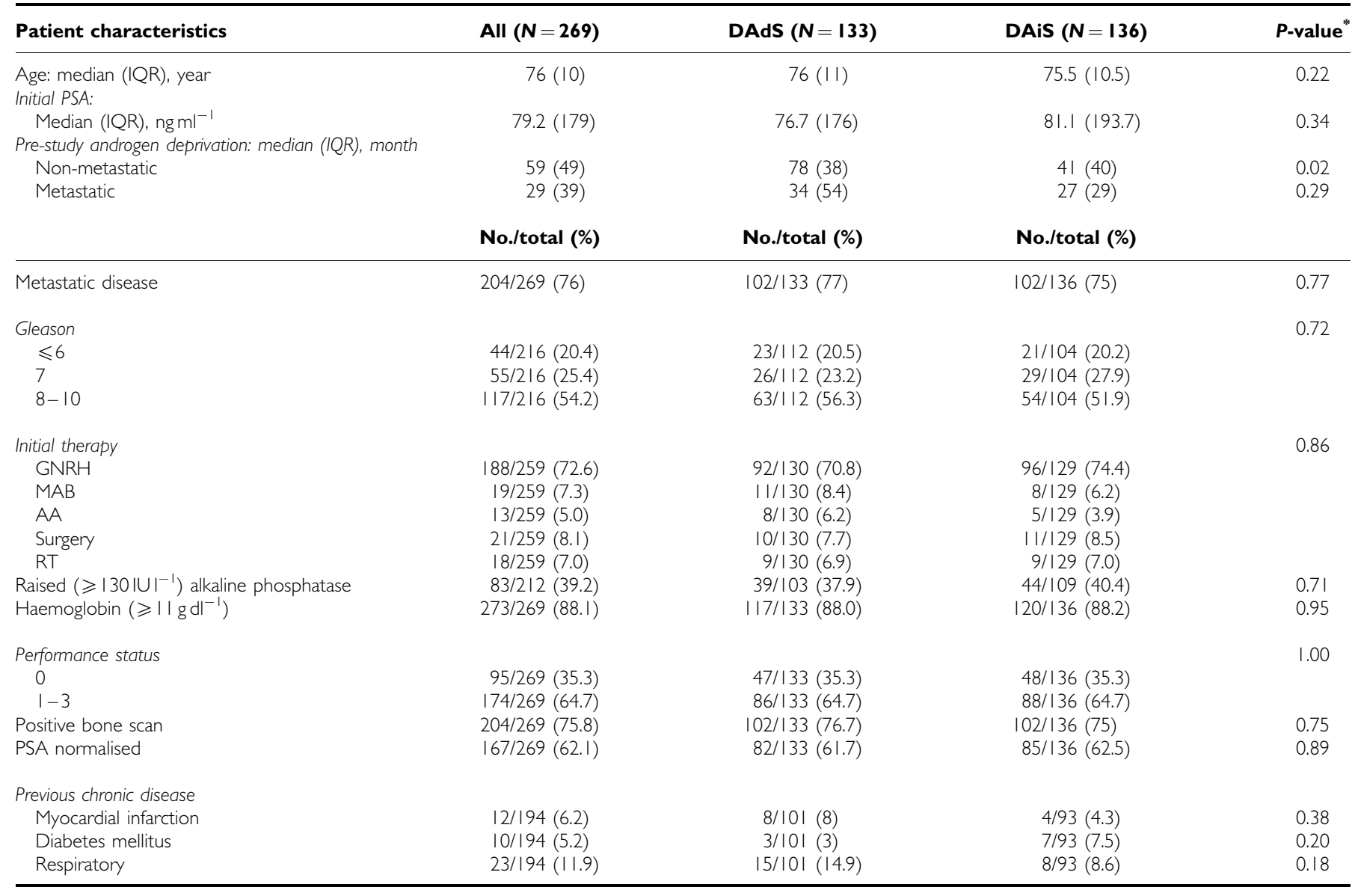

Abbreviations: $\mathrm{AA}=$ anti-androgen; $\mathrm{DAiS}=$ Dexamethasone, Aspirin, and immediate addition of Diethylstilbestrol; DAdS = Dexamethasone, Aspirin, and deferred (until disease progression) Diethylstilbestrol; $\mathrm{GnRH}=$ gonadorelin analogue; $\mathrm{IQR}=$ inter-quartile range; $M A B=$ maximum androgen blockade; $P S A=$ prostate-specific antigen; $\mathrm{RT}=$ radiotherapy. * P-values refer to differences between patients receiving DAdS and DAiS.

Overall, 12 patients required oestrogen substitution because of the manufacturing shortage of Diethylstilbestrol. Therefore, the multivariable analyses were also repeated by excluding these patients, per protocol analysis, but no difference in terms of response rate, TTP and PFS, as well as in overall survival between DAiS and DAdS was found.

\section{Toxicity}

The toxicity was compared between DAiS and DA (before adding Diethylstilbestrol) in Table 4. The most serious events were those due to VTE. The incidence of these was $22 \%(n=28)$ in DAiS and $11 \%(n=14)$ in the DA arm $(P=0.02)$. In the DAds arm, three VTEs occurred, whilst on Dexamethasone and aspirin alone, 11 occurred following the addition of Diethylstilbestrol. One TIA occurred on DAiS. The risk of VTEs varied with time on treatment. The risk reached a maximum after 5 months of therapy and then tailed off; see Figure 3. In $60 \%$ of patients, it was possible to anticoagulate and to continue hormonal therapy.

Painful gynaecomastia occurred in only $1 \%$ on DA and in $40 \%$ on DAiS $(P=0.001)$. Fluid retention was more common in DaiS, although it occurred in DA as well ( 49 vs $42 \%: P=0.26)$. Overall dose reductions were made in $34 \%$ of patients (39\% on the DA arm and $30 \%$ on the DAiS arm $P>0.05)$. No significant differences in weight gain were seen in the two arms $(11 \%$ on DA and $14.0 \%$ on DAS: $P=0.47)$.

\section{Quality of life}

Multivariate analysis of variance showed no significant differences in quality of life measures of the QLQ-C30 questionnaire between the two treatment arms over time, although pre-study performance status had a significant effect on their quality of life (Table 5). However, the sample data (see Table 6) showed that the patients in DAiS group felt that they had slightly better global health and sleep compared with the patients in DAdS group. Similarly, there was no significant difference in prostate-specific symptoms of the EORTC-PR25 between the two treatment arms over the study time (MANOVA: Wilks' $\lambda$, $\left.\mathrm{F}_{5,106}=0.97, P<0.66\right)$. However, sample data showed that patients in DAiS group felt that wearing an incontinence aid posed more problems for them compared with the patients in DAdS group (see Table 7).

\section{DISCUSSION}

This study reports that the treatment strategies of immediate $v s$ deferred Diethylstilbestrol do not differ significantly in terms of efficacy in the management of CRPC. Despite a slightly higher (nonsignificant) PSA response rate (68\%) in the DAiS arm (with immediate use of Diethylstilbestrol), deferring its use until failure of Dexamethasone and aspirin (response rate 64\%) might be the preferred strategy as PFS, overall survival, and quality of life did not reduce significantly, and there was a significantly reduced number of VTEs and painful gynaecomastia. Previous therapy and 


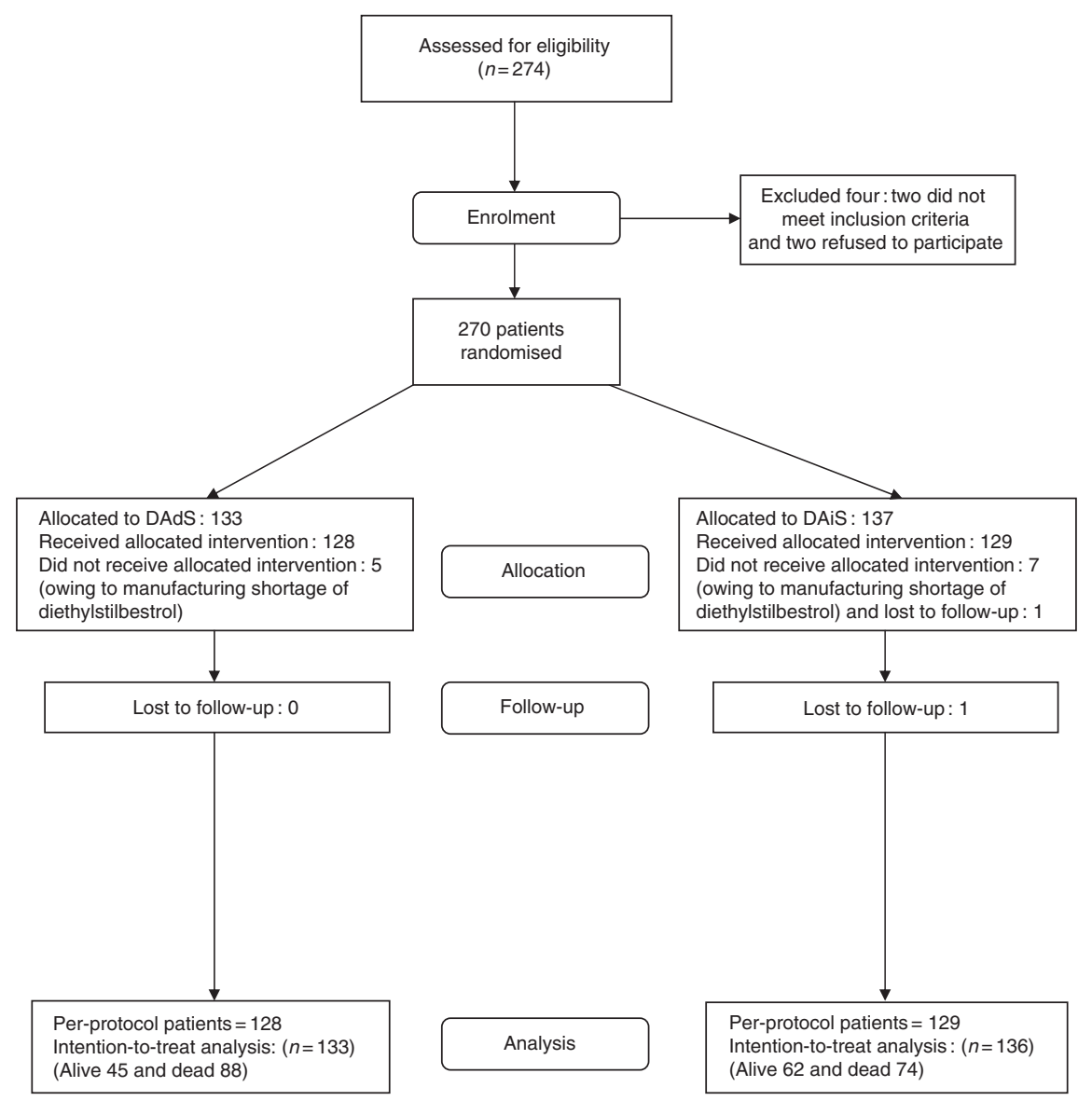

Figure I The consort flow diagram.

Table 2 Response to immediate (concurrent) vs deferred (sequential) Diethylstilbestrol

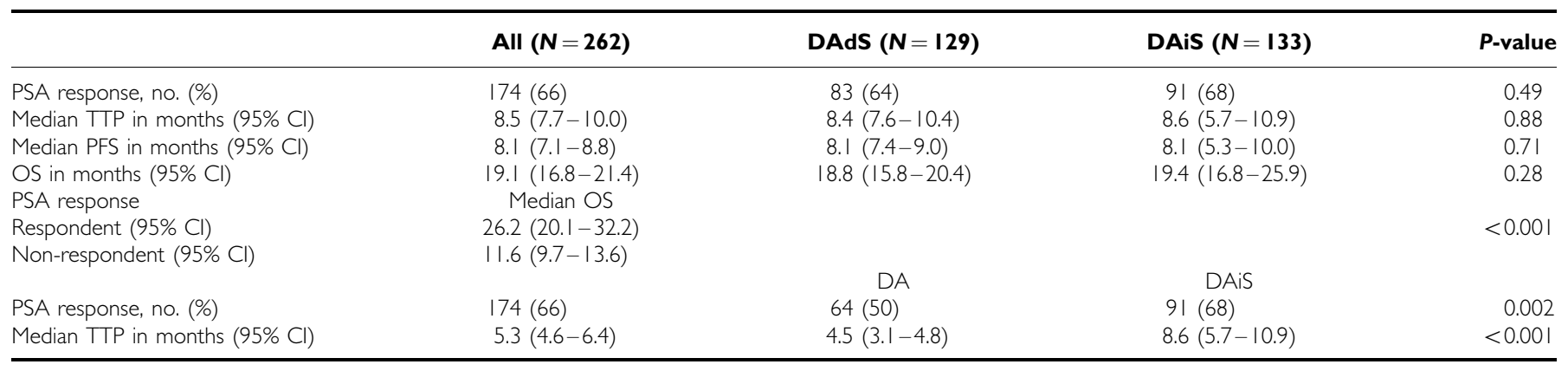

Abbreviations: $\mathrm{Cl}=$ confidence interval; $\mathrm{DA}=$ Dexamethasone and Aspirin; DAiS=Dexamethasone, Aspirin, and immediate addition of Diethylstilbestrol; DAdS = Dexamethasone, Aspirin, and deferred (until disease progression) Diethylstilbestrol; OS = overall survival; PSA = prostate-specific antigen; TTP = time to progression

haemoglobin had significant effect on patients' overall survival rather than the treatment when adjusted for other baseline prognostic factors. Treatment sequencing did not affect the quality of life but pre-treatment performance status did. However, the response rate for the DAiS $(68 \%)$ was significantly higher than the response rate of DAdS (before adding Diethylstilbestrol) $(50 \%)(P=0.002)$. Similarly, the median TTP for DAiS (8.6 months) was significantly longer than that of DAdS (4.5 months) $(P<0.001)$.

The failure to mandate continuous gonadorelin therapy throughout the trial has meant that some patients were not biochemically castrate in the DAdS arm. This could be considered as a shortcoming of the study - and in $22 \%$ of cases, testosterone recovery did occur, however this group's overall time to progression was the same as those who remained castrate, which was reassuring.

Reduction in PSA by $50 \%$ was associated with an overall survival advantage (Table 2). Recently, the importance of the reduction in PSA with chemotherapy has been questioned. Indeed, in the recently updated guidelines for reporting of Phase II studies in CRPC (Scher et al, 2008), the quoting of a PSA $50 \%$ reduction rate has been abandoned. It would seem that this might be premature wherein the agent concerned targets the androgen receptor as opposed to functioning independently of it.

Quality of life was assessed monthly during this study and there was no improvement conferred by the immediate use of Diethylstilbestrol. In particular, the PR25 prostate-specific questionnaire failed to show an improvement, suggesting that lower urinary tract 


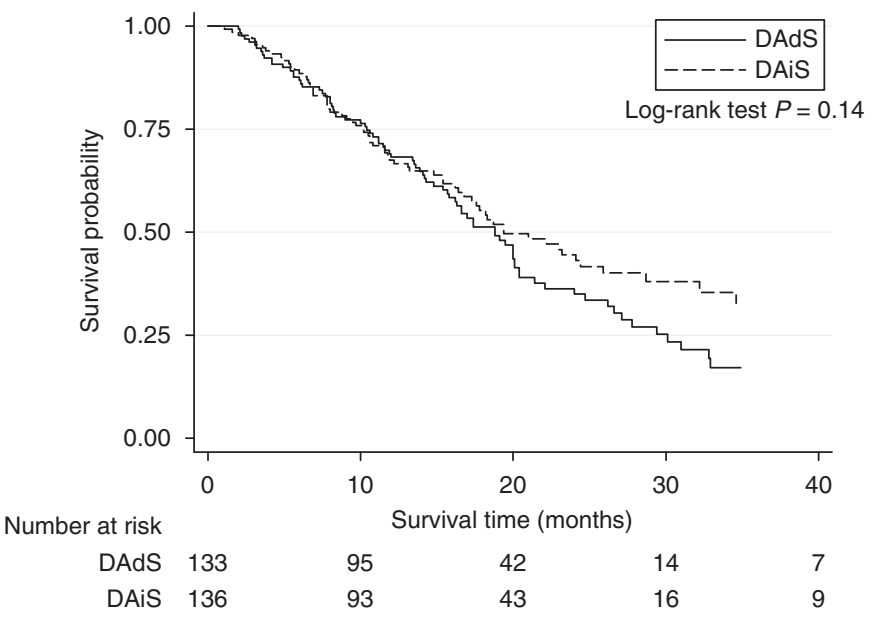

Figure 2 Overall survival according to immediate vs deferred Diethylstilbestrol.

Table 3 Multivariable Cox proportional hazards model for concurrent vs sequential treatment based on overall survival (stratified by performance status, PSA response to previous therapy and bone scan) ${ }^{\mathrm{a}}$

\begin{tabular}{|c|c|c|}
\hline Characteristic & Hazard ratio $(95 \% \mathrm{Cl})^{\mathrm{b}}$ & $P$-value \\
\hline Age (in years) & $0.70(0.49-1.00)$ & 0.051 \\
\hline Age square & $1.0025(1.00049-1.00502)$ & 0.046 \\
\hline Treatment & & 0.16 \\
\hline DAdS & 1 & \\
\hline DAiS & $0.69(0.41-1.16)$ & \\
\hline Haemoglobin & & 0.004 \\
\hline$<\| \mathrm{g} \mathrm{dl}^{-1}$ & 1 & \\
\hline$\geqslant|| \mathrm{gdl}^{-1}$ & $0.44(0.25-0.77)$ & \\
\hline Alkaline phosphatase & & 0.93 \\
\hline$<1.5 \times$ ULN & 1 & \\
\hline$\geqslant 1.5 \times$ ULN & $0.97(0.55-1.7 \mathrm{I})$ & \\
\hline Gleason & & 0.49 \\
\hline$\leqslant 6$ & 1 & \\
\hline 7 & $0.82(0.40-|.7|)$ & \\
\hline $8-10$ & $0.68(0.35-1.30)$ & \\
\hline Prior therapy & & 0.01 \\
\hline $\mathrm{GnRH}$ & 1 & \\
\hline $\mathrm{AA}$ & $5.38(1.99-14.58)$ & \\
\hline MAB & $1.91(0.90-4.07)$ & \\
\hline $\begin{array}{l}\text { Radical treatment } \\
\text { (radiotherapy or surgery) }\end{array}$ & $1.38(0.76-2.50)$ & \\
\hline Diabetes & & 0.44 \\
\hline Absent & 1 & \\
\hline Present & $0.68(0.25-1.81)$ & \\
\hline Myocardial infarction & & 0.13 \\
\hline Absent & 1 & \\
\hline Present & $2.07(0.81-5.27)$ & \\
\hline Respiratory disease & & 0.44 \\
\hline Absent & 1 & \\
\hline Present & $0.73(0.33-1.62)$ & \\
\hline
\end{tabular}

Abbreviations: $\mathrm{AA}=$ anti-androgen; $\mathrm{DA} \mathrm{AS}=$ Dexamethasone, Aspirin, and immediate addition of Diethylstilbestrol; DAdS = Dexamethasone, Aspirin, and deferred (until disease progression) Diethylstilbestrol; $\mathrm{Cl}=$ confidence interval; $\mathrm{GNRH}=$ gonadorelin analogues; $M A B=$ maximum androgen blockade; PSA = prostate-specific antigen; ULN = upper limit of normal. ${ }^{a}$ Analysis was restricted to patients without missing values $(n=164)$. ${ }^{b}$ Hazard ratios are adjusted for all variables displayed in the table.
Table 4 Comparison of toxicity between DA and DAiS

\begin{tabular}{|c|c|c|c|c|}
\hline Toxicity & $\begin{array}{c}\text { All }(N=257) \\
N(\%)\end{array}$ & $\begin{array}{c}\text { DA }(N=128) \\
N(\%)\end{array}$ & $\begin{array}{c}\text { DAiS }(N=129) \\
N(\%)\end{array}$ & $P$-value \\
\hline $\begin{array}{l}\text { Painful } \\
\text { gynaecomastia }\end{array}$ & $52(20)$ & I (0I) & $51(40)$ & $<0.001$ \\
\hline Headaches & $28(||)$ & $16(13)$ & $12(09)$ & 0.31 \\
\hline Skin & $134(52)$ & $59(46)$ & $65(50)$ & 0.52 \\
\hline Fluid retention & $117(46)$ & $54(42)$ & $63(49)$ & 0.26 \\
\hline Weight gain & $32(13)$ & $14(11)$ & $18(14)$ & 0.47 \\
\hline Myopathy & $5(02)$ & $4(03)$ & I (0I) & 0.25 \\
\hline Hyperglycaemia & $4(02)$ & $3(02)$ & I (0I) & 0.51 \\
\hline VTE & $42(16)$ & $14(11)$ & $28(22)$ & 0.02 \\
\hline DVT & $20(08)$ & $3(03)$ & $17(13)$ & \\
\hline PE & $21(08)$ & II (09) & $10(08)$ & \\
\hline TIA & I (0.5) & $0(0)$ & I (0I) & \\
\hline
\end{tabular}

Abbreviations: DA = Dexamethasone and Aspirin; DAiS = Dexamethasone, Aspirin, and immediate addition of Diethylstilbestrol; DVT = deep venous thrombosis; $\mathrm{PE}=$ pulmonary embolism; $\mathrm{TIA}=$ transient ischaemic attack; $\mathrm{VTE}=$ veno-thromboembolic disease.

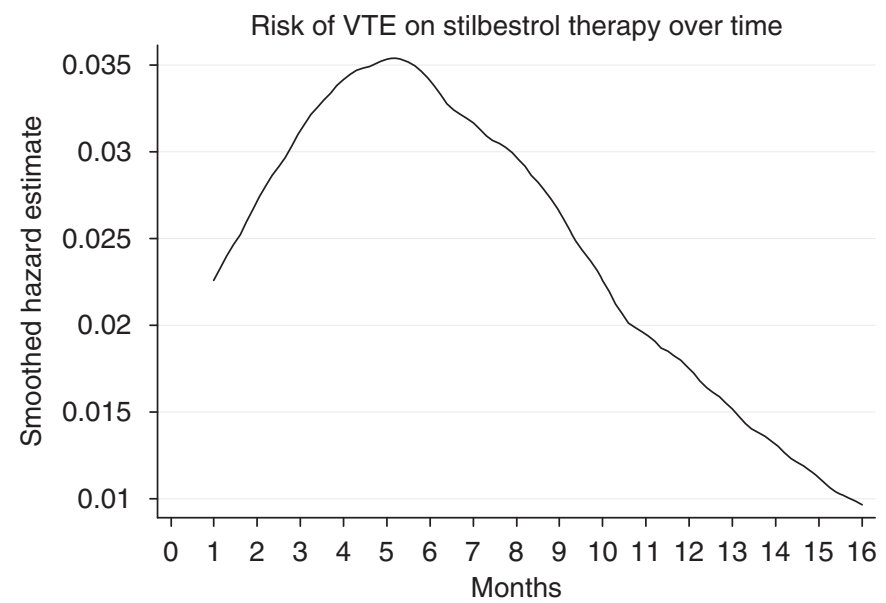

Figure 3 The risk of veno-thromboembolic events (VTE) from start of Diethylstilbestrol therapy over time.

Table 5 Multivariate analysis of variance based on EOTC-QLQ-C30 in terms of immediate vs deferred Diethylstilbestrol and other stratifying factors

\begin{tabular}{lcccc}
\hline Factor & Statistic & d.f. & $\mathbf{F}_{(\text {d.f. }, \text {,d.f.2) }}$ & P-value \\
\hline Treated with DAiS & 0.91 & $\mid$ & $1.01_{(15,159)}$ & 0.44 \\
Bad performance & 0.85 & $\mid$ & $1.83_{(15,159)}$ & 0.03 \\
Metastatic disease & 0.87 & $\mid$ & $1.59_{(15,159)}$ & 0.08 \\
PSA normalised & 0.89 & $\mathrm{I}$ & $1.30_{(15,159)}$ & 0.21 \\
\hline
\end{tabular}

Abbreviations: DAiS = Dexamethasone, Aspirin, and immediate addition of Diethylstilbestrol; d.f. $=$ degrees of freedom; PSA = prostate-specific antigen.

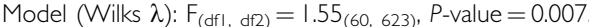

symptoms were not helped by Diethylstilbestrol specifically. As in many studies, quality of life assessment has its limitations; there was a $26 \%$ failure to complete the forms, but this was not related to treatment (equally distributed between the two arms).

Overall, the treatments were reasonably tolerated. Diethylstilbestrol and Dexamethasone given together were associated with increased toxicity. The development of VTE was associated with the use of Diethylstilbestrol, although at this relatively low dose, the rate was manageable with no suggestion of excess mortality in this study. Moreover, many patients were able to continue Diethylstilbestrol with 
Table 6 Differences in quality of life scores (based on EORTC-QLQC30) in terms of immediate vs deferred Diethylstilbestrol

\begin{tabular}{lrrc} 
& \multicolumn{2}{c}{$\begin{array}{c}\text { Mean \% change from baseline function and } \\
\text { symptom scores over the study period }\end{array}$} \\
\cline { 2 - 4 } Scale & DAiS & DAdS & DAiS-DAdS \\
\hline Physical functioning & -0.29 & -4.66 & 4.95 \\
Role functioning & -1.76 & -4.93 & 3.17 \\
Emotional functioning & 1.36 & 0.42 & 0.94 \\
Cognitive functioning & -0.16 & 1.23 & -1.39 \\
Social functioning & 2.79 & -2.77 & 5.56 \\
Global health status/QOL & 0.61 & -6.97 & 7.58 \\
Fatigue & 0.27 & 5.17 & -4.9 \\
Nausea and vomiting & -0.92 & -0.89 & -0.03 \\
Pain & -9.46 & -4.29 & -5.17 \\
Dyspnoea & 5.65 & 9.69 & -4.04 \\
Insomnia & -6.02 & 0.76 & -6.78 \\
Appetite loss & -10.47 & -6.12 & -4.35 \\
Constipation & -8.59 & -4.73 & -3.86 \\
Diarrhoea & 4.08 & 4.08 & 0 \\
Financial difficulties & -0.14 & -1.41 & 1.27 \\
\hline Dinger & & &
\end{tabular}

Abbreviations: DAiS = Dexamethasone, Aspirin, and immediate addition of Diethylstilbestrol; DAdS = Dexamethasone, Aspirin, and deferred (until disease progression) Diethylstilbestrol; $\mathrm{QOL}=$ quality of living.

Table 7 Differences in site-specific quality of life scores (based on EORTC-QLQ-PR25) in terms of immediate vs deferred Diethylstilbestrol

\begin{tabular}{lccc}
\hline & \multicolumn{2}{c}{$\begin{array}{c}\text { Mean \% change from baseline } \\
\text { scores over the study period }\end{array}$} \\
\cline { 2 - 4 } Scale & DAiS & DAdS & DAiS-DAdS \\
\hline Urinary symptoms & -0.51 & -0.43 & -0.08 \\
Bowel symptoms & 0.25 & -0.24 & 0.49 \\
Hormone treatment related symptoms & 0.48 & -0.20 & 0.68 \\
Incontinence aid & 11 & 2.53 & 8.47 \\
Sexual activity & -0.36 & -0.50 & 0.14 \\
Sexual function & -0.23 & -0.13 & -0.10 \\
\hline
\end{tabular}

Abbreviations: DAiS = Dexamethasone, Aspirin, and immediate addition of Diethylstilbestrol, DAdS = Dexamethasone, Aspirin, and deferred (until disease progression) Diethylstilbestrol.

concomitant anticoagulation. There were no documented myocardial infarcts or development of angina on this agent.

Dexamathasone and aspirin was well tolerated with good response rates $(50 \%)$. The most common toxicities were bruising and fluid retention. It is surprising that so many developed fluid retention, as Dexamethasone is considered to be a pure glucocorticoid. It is possible that the use of aspirin at the same time influenced this. Overall, 34\% required dose reduction of Dexamethasone, and clearly as lower doses can produce PSA responses, starting with a smaller dose and escalating might be an alternative strategy, particularly in asymptomatic patients with rising PSA. Several groups (Nishimura et al, 2000; Venkitaraman et al, 2008), have demonstrated the value of low-dose Dexamethasone (500 m.c.g. per day) in terms of efficacy and toxicity. However, there is a suggestion of a PSA response to increasing doses (Nishimura et al, 2000). In patients with symptomatic disease, the improvement in appetite and weight that result from a higher dose of Dexamethasone might be more appealing, as dose escalation takes time.

When reviewed for prognostic factors, it is clear that previously identified prognostic factors from other studies apply here (Hussain et al, 2006). We could not identify a particular subgroup that benefitted from either treatment approach. The effect of pretreatment haemoglobin was particularly striking with a hazard ratio of $0.44(P=0.004)$ for overall survival, confirming the finding in many cancers that the development of anaemia is a strong adverse prognostic factor. Patients treated with AAs monotherapy fared worse, despite the fact that they needed to be biochemically castrate before study entry (via addition of $\mathrm{GnRH}$ analogue).

Until recently, there was a feeling that further hormone manipulations beyond androgen deprivation offered little other than transient falls in PSA, and that docetaxel-based chemotherapy should be offered for a majority following the failure of conventional androgen deprivation. It is becoming clearer that major benefits might be obtained with further hormone therapies; the interest in the drug abiraterone is supportive of this (Attard et al, 2009).

This study sheds some light on the immediate $v s$ deferred addition of Diethylstilbestrol with Dexamethasone and Aspirin in treating patients with CRPC. Current thinking attributes prostate cancer growth and development to stimulation of the androgen receptor even at low-plasma testosterone levels (Attard et al, 2008). Others speculate that mutations may confer a broader range of potential ligand binding (Grigoryev et al, 2000; Sun et al, 2006), including corticosteroids and oestrogens. This hypothesis would explain the findings of this study, in that both drugs bind to the $\mathrm{AR}$, but that Diethylstilbestrol has broader activity. To prove this, it would be necessary to reverse the sequence of study drugs, however, the fact that Dexamethasone has fewer severe side effects makes this unattractive.

It is possible that response to Diethylstilbestrol may have required the presence of Dexamethasone. It would have been impractical to insist that Dexamethasone be removed when Diethylstilbestrol started, in view of the fact that many would have been on it for some time making rapid withdrawal unsafe. It would have been useful to measure adrenal androgens and their precursors during the study to see whether they were related to response, and this and the addition of other translational end points would have strengthened the study. Several other shortcomings of the study were apparent. The study commenced before the docetaxel era making its usage infrequent in the study, although its use became more frequent as the study progressed. It is unclear whether this affected the outcome. In addition, the recent publication of two studies have lead to the conclusion that radiotherapy has a valuable role in the management of patients with locally advanced disease, suggesting that the number of such patients requiring systemic treatment for local progression will fall (Mottet et al, 2010; Warde et al, 2010). Disproportionate dose reduction of Dexamethasone (39\% on the DA arm and $30 \%$ on the DAiS arm, $P=0.12$ ) might affect the study outcome slightly. Finally, as study entry required a rise in PSA, rather than progression on imaging, patients whose prostate cancer did not express PSA were not included.

In conclusion, the immediate or deferred use of Diethylstilbestrol with Dexamethasone to manage CRPC differs neither in terms of PSA response rate nor in terms of PFS. Moreover, there was no suggestion of significant difference in overall survival or in quality of life. Given the significantly higher toxicity of Diethylstilbestrol, deferring Diethylstilbestrol until failure of Dexamethasone is the preferred strategy when using these agents in CRPC. The use of hormonal agents following failure of chemotherapy for what was previously termed as hormone refractory disease is becoming more accepted (Shamash et al, 2008), and the use of such agents post chemotherapy warrants further investigation.

\section{Conflict of interest}

The authors declare no conflict of interest.

\section{ACKNOWLEDGEMENTS}

This study was supported by Barts and the London NHS Trust sponsored this study, taking on the legal responsibility for the 
initiation and management of the research, ensuring the study was carried out in compliance with all UK regulatory bodies. The coordination of this trial was funded entirely by a core grant from Orchid, which supported staff and administration costs associated with trial design, coordination, and data analysis. We thank the National Cancer Research Network who adopted this trial into their portfolio and Consultant Urological Surgeons at all sites who assisted in the screening of patients for recruitment into the study.

\section{Author contributions}

Jonathan Shamash was the Chief Investigator for this trial. He was responsible for trial conception and had full access to all the data in the study and takes responsibility for the integrity of the data and the accuracy of the data analysis.

Study concept and design: J Shamash, T Oliver

Acquisition of data: P Wilson, N Tranter

Analysis and interpretation of data: J Shamash, T Powles, P Wilson, S J Sarker

Drafting of manuscript: J Shamash, S J Sarker

Critical revision of the manuscript for important intellectual content: T Powles

Statistical analysis: S J Sarker, P Wilson

Administrative, technical, or material support: $S$ McFaul, N O'Brien, N Tranter

Study supervision: J Shamash
Participating centres and clinicians - $(274$ recruited patients in total)

St Bartholomew's Hospital, London: J Shamash, RTD Oliver, T Powles (66); Queens Hospital, Romford: J Shamash (66); Churchill Hospital, Oxford: A Protheroe (39); Kent and Canterbury Hospital: N Mithal (29); Norfolk and Norwich University Hospital: R Mills (14); Worthing Hospital: R Beard (11); Royal Sussex County Hospital, Brighton: A Robinson (9); William Harvey Hospital, Kent: N Mithal (9); Bristol Haematology and Oncology Centre: A Bahl (7); Torbay District General Hospital, Torquay: S MacDermott (7); Warwick Hospital: C Humber (5); Raigmore Hospital, Inverness: K Kelly (4); Chelsea and Westminster Hospital: C Brock (2); Scunthorpe Hospital: S Dixit (2); George Elliott Hospital, Warwickshire: J Worlding (1); Grimsby Hospital: S Dixit (1); Hammersmith Hospital: S Mangar (1); Walsgrave Hospital, Coventry: A Stockdale (1).

\section{Research nurses at participating centres}

St Bartholomew's Hospital, Whipps Cross Hospital, London: S McFaul; Queens Hospital, Romford: N O'Brien; Churchill Hospital, Oxford: J Boutflower; Kent and Canterbury Hospital: J Severn, J Buckley; Norfolk and Norwich University Hospital: S Penny; Worthing Hospital: N Turner; Royal Sussex County Hospital, Brighton: L Corbett, J Dexter; William Harvey Hospital, Kent: R Hulbert; Bristol Haematology and Oncology Centre: P Gingell; Torbay District General Hospital, Torquay: S Forbes; Warwick Hospital: E Simmons; Raigmore Hospital: G Simpson; and Scunthorpe Hospital: K Dent, S Pearson.

\section{REFERENCES}

Attard G, Reid AH, A'Hern R, Parker C, Oommen NB, Folkerd E, Messiou C, Molife LR, Maier G, Thompson E, Olmos D, Sinha R, Lee G, Dowsett M, Kaye SB, Dearnaley D, Kheoh T, Molina A, de Bono JS (2009) Selective inhibition of CYP17 with abiraterone acetate is highly active in the treatment of castration-resistant prostate cancer. J Clin Oncol 27(23): $3742-3748$

Attard G, Reid AH, Yap TA, Raynaud F, Dowsett M, Settatree S, Barrett M, Parker C, Martins V, Folkerd E, Clark J, Cooper CS, Kaye SB, Dearnaley D, Lee G, de Bono JS (2008) Phase I clinical trial of a selective inhibitor of CYP17, abiraterone acetate, confirms that castration-resistant prostate cancer commonly remains hormone driven. J Clin Oncol 26(28): 4563-4571

Bubley GJ, Carducci M, Dahut W, Dawson N, Daliani D, Eisenberger M, Figg WD, Freidlin B, Halabi S, Hudes G, Hussain M, Kaplan R, Myers C, Oh W, Petrylak DP, Reed E, Roth B, Sartor O, Scher H, Simons J, Sinibaldi V, Small EJ, Smith MR, Trump DL, Vollmer R, Wilding G (1999) Eligibility and response guidelines for phase II clinical trials in androgen-independent prostate cancer: recommendations from the Prostate-Specific Antigen Working Group. J Clin Oncol 17(11): $3461-3467$

Farrugia D, Ansell W, Singh M, Philp T, Chinegwundoh F, Oliver RT (2000) Stilboestrol plus adrenal suppression as salvage treatment for patients failing treatment with luteinizing hormone-releasing hormone analogues and orchidectomy. BJU Int 85(9): $1069-1073$

Fossa SD, Slee TPH, Brausi M, Horenblas S, Hall RR, Hetherington JW, Aaronson N, Prijck L, de Collette L (2001) Flutamide $v s$ Prednisone in patients with prostate cancer symptomatically progressing after androgen ablative therapy - a phase III study of the European Organization for Reseach and Treatment of Cancer Genitourinary Group. J Clin Oncol 19: $62-71$

Grigoryev DN, Long BJ, Njar VC, Brodie AH (2000) Pregnenolone stimulates LNCaP prostate cancer cell growth via the mutated androgen receptor. J Steroid Biochem Mol Biol 75(1): 1-10

Hellerstedt BA, Pienta KJ (2002) The current state of hormonal therapy for prostate cancer. CA Cancer J Clin 52(3): 154-179

Hussain M, Tangen CM, Higano C, Schelhammer PF, Faulkner J, Crawford ED, Wilding G, Akdas A, Small EJ, Donnelly B, MacVicar G, Raghavan D (2006) Absolute prostate-specific antigen value after androgen deprivation is a strong independent predictor of survival in new metastatic prostate cancer: data from Southwest Oncology Group Trial 9346 (INT-0162). J Clin Oncol 24(24): 3984-3990
Kantoff PW, Halabi S, Conaway M, Picus J, Kirshner J, Hars V, Trump D, Winer EP, Vogelzang NJ (1999) Hydrocortisone with or without mitoxantrone in men with hormone-refractory prostate cancer: results of the cancer and leukemia group B 9182 study. J Clin Oncol 17(8): 2506-2513

Machin D, Campbell M, Tan SB, Tan SH (2008) Sample Size Tables for Clinical Studies, 3rd edn, Blackwell: Oxford, UK

Mottet N, Peneau M, Mazeron J, Molinie VPR (2010) Impact of radiotherapy (RT) combined with androgen deprivation (ADT) vs ADT alone for local control in clinically locally advanced prostate cancer. Proc ASCO 4505: 343S

Nishimura K, Nonomura N, Yasunaga $\mathrm{Y}$, Takaha N, Inoue H, Sugao $\mathrm{H}$, Yamaguchi S, Ukimura O, Miki T, Okuyama A (2000) Low doses of oral dexamethasone for hormone-refractory prostate carcinoma. Cancer 89(12): $2570-2576$

Petrylak DP, Tangen CM, Hussain MH, Lara Jr PN, Jones JA, Taplin ME, Burch PA, Berry D, Moinpour C, Kohli M, Benson MC, Small EJ, Raghavan D, Crawford ED (2004) Docetaxel and estramustine compared with mitoxantrone and prednisone for advanced refractory prostate cancer. N Engl J Med 351(15): $1513-1520$

Scher HI, Halabi S, Tannock I, Morris M, Sternberg CN, Carducci MA, Eisenberger MA, Higano C, Bubley GJ, Dreicer R, Petrylak D, Kantoff P, Basch E, Kelly WK, Figg WD, Small EJ, Beer TM, Wilding G, Martin A, Hussain M (2008) Design and end points of clinical trials for patients with progressive prostate cancer and castrate levels of testosterone: recommendations of the Prostate Cancer Clinical Trials Working Group. J Clin Oncol 26(7): 1148-1159

Shamash J, Davies A, Ansell W, McFaul S, Wilson P, Oliver T, Powles T (2008) A phase II study investigating the re-induction of endocrine sensitivity following chemotherapy in androgen-independent prostate cancer. Br J Cancer 98(1): 22-24

Sun C, Shi Y, Xu LL, Nageswararao C, Davis LD, Segawa T, Dobi A, McLeod DG, Srivastava S (2006) Androgen receptor mutation (T877A) promotes prostate cancer cell growth and cell survival. Oncogene 25(28): $3905-3913$

Tannock IF, de Wit R, Berry WR, Horti J, Pluzanska A, Chi KN, Oudard S, Theodore C, James ND, Turesson I, Rosenthal MA, Eisenberger MA (2004) Docetaxel plus prednisone or mitoxantrone plus prednisone for advanced prostate cancer. $N$ Engl J Med 351(15): $1502-1512$

Tannock IF, Osoba D, Stockler MR, Ernst DS, Neville AJ, Moore MJ, Armitage GR, Wilson JJ, Venner PM, Coppin CM, Murphy KC (1996) Chemotherapy with mitoxantrone plus prednisone or prednisone 
alone for symptomatic hormone-resistant prostate cancer: a Canadian randomized trial with palliative end points.(see comment). J Clin Oncol 14(6): $1756-1764$

The CONSORT statement: revised recommendations for improving the quality of reports of parallel group randomized trials, D Moher, KF Schulz, DG Altman, BMC Med Res Methodol 2001, 1: 2

Venkitaraman R, Thomas K, Huddart RA, Horwich A, Dearnaley DP, Parker CC (2008) Efficacy of low-dose dexamethasone in castrationrefractory prostate cancer. BJU Int 101(4): $440-443$
Warde PR, Mason MD, Sydes MR, Gospodarowicz MK, Swanson GP, Kirkbride P, Kostashuk E, Hetherington J, Ding K, Parulekar W (2010) Intergroup randomized phase III study of androgen deprivation therapy (ADT) plus radiation therapy (RT) in locally advanced prostate cancer (CaP) (NCIC-CTG, SWOG, MRC-UK, INT: T94-0110; NCT00002633). Proc ASCO CRA 4504: 959S

Yoshimura R, Sano H, Masuda C, Kawamura M, Tsubouchi Y, Chargui J, Yoshimura N, Hla T, Wada S (2000) Expression of cyclooxygenase-2 in prostate carcinoma. Cancer 89(3): 589-596 